\title{
A DIGITAL BRIDGE FOR COLLABORATION IN CULTURAL HERITAGE
}

\author{
${ }^{1}$ A. Psenner, Institute for Urban Design and Landscape Architecture, Urban Structure Studies, TU Wien, Vienna, Austria \\ - angelika.psenner@tuwien.ac.at \\ ${ }^{2}$ F. Hauer, Institute for Urban Design and Landscape Architecture, Urban Design Research Unit, TU Wien, Vienna, Austria \\ - friedrich.hauer@tuwien.ac.at \\ ${ }^{3}$ A. Antoniou, Department of Architecture, University of Florence, Florence, Italy - aristotelis.antoniou@stud.unifi.it \\ College of Architecture and Urban Planning, Tongji University, Shanghai, China \\ ${ }^{4}$ A. Rejentova, Department of Architecture and Design, TU Wien, Vienna, Austria - \\ e11929148@student.tuwien.ac.at \\ College of Architecture and Urban Planning, Tongji University, Shanghai, China \\ ${ }^{5}$ P. Toto, Department of Architecture and Civil Engineering, University of Pavia, Pavia, Italy - \\ paolo.toto01@universitadipavia.it \\ College of Architecture and Urban Planning, Tongji University, Shanghai, China
}

KEY WORDS: Mapping Heritage, Cartography, Crowdsourcing, Collaborative Data Exchange, Big Data, Linking World Heritage Stakeholders

\begin{abstract}
:
The importance of history and the role that culture plays on the population is well defined, but we have never researched culture in a truly collective way. Data digitisation and archiving could be transformed into an exceptional tool for connecting all different users and sectors of cultural heritage into a "Global heritage" interaction and communication. The research undertaken is summarised to the development of a crowdsourcing, interdisciplinary platform, under the name "Heritage for People".

The paper consists of 6 sections. The first of these concerns a general description of the problem, linked to the risks of cultural heritage. A closer analysis of the risks present in the historic center of Vienna follows. The third paragraph deals with the tools for planning and protecting the cultural heritage of the Austrian capital. The fourth section introduces the "Heritage for People" tool in which a new online platform is outlined. The fifth chapter is instead dedicated to a description of the possible technologies to be used, while the last section illustrates how the proposed platform can have other applications depending on the cultural heritage.
\end{abstract}

\section{INTRODUCTION}

The conflict between the desire to modernize large metropolises and the desire to preserve the artistic, historical and cultural heritage has always represented a considerable problem for the municipalities. Bad management of the heritage, not careful reading of the context, lack of knowledge and incorrect urban planning can inflict enormous damage on the legacy that has been handed over to us from the past, often irreversible damage. What the different figures involved in the planning of the metropolis ask themselves is if there is, in some way, a way to no longer see cultural heritage and modern architecture as eternal enemies. These two elements, through a wise exploitation of existing technologies, can represent a perfectly functioning combination in cities where desire for the future meets passion for the past. Contemporary architecture and cultural heritage can coexist in a single context when knowledge of the former represents a starting point for the latter. Underlying all this is a need for knowledge and collaboration between the different actors, such as architects, urban planners, members of the local and non-local community, municipalities and others. A modern and sustainable way to connect all these actors is the development of a system of data exchange, loading and unloading, through which knowledge becomes an asset for everyone.

\section{WORLD HERITAGE LIST IN DANGER}

When today we hear about cultural heritage in various fields, unfortunately, the first thought that is grasped is not that which concerns the wonders and outstanding values linked to it, but rather the danger and the need for protection in which the cultural heritage, today, is found. Starting from the first examples of becoming aware of what the past had to pass on to future generations, man has undertaken a series of measures, strategies, functional programs and countless other activities aimed at the protection of cultural heritage. The first steps towards this direction date back to the sixteenth century, more precisely to 1515, when Pope Leo X appointed "The Divine Painter" Raffello Sanzio as 'Inspector of Fine Arts'.

Since then things have drastically changed, more attention is paid to the wonders that we inherit, day after day, from the past. What has not changed, however, is the dangers that afflict the cultural heritage. The greatest enemy of the latter is certainly time. In fact, the "technological" risks are those that concern the techniques with which more or less ancient artifacts were made. These techniques, to date, are difficult to recover due to a series of factors, such as materials no longer available, lack of information due to deterioration or the lack of craftsmen. Another factor that falls into the category of risks is the environmental factor. The latter, due to increasingly sudden changes, is becoming an element that can no longer be underestimated in the prevention and protection of assets. 
Global warming, floods, earthquakes, and much more require ongoing maintenance. Wishing to conclude this short but summary list of risks, the anthropic factor certainly finds its place. All the potential risks deriving from human action are collected within this category. Starting with pollution, neglect, vandalism, over-tourism and, unfortunately, even restoration operations carried out completely incorrectly.

Awareness of what is happening can in this case be an excellent tool for preventing these risks. For this reason, UNESCO has compiled a list of world heritage sites considered in danger. This document is called "List in Danger" and provides for the collection of all world heritage sites for which conservation and greater protection actions are necessary. The aim is therefore to increase both knowledge and awareness of the 'ease' with which heritage can be under threat. The aim is also to encourage and raise awareness in the community to take measures for heritage conservation and risk mitigation.

This is how it reads on the UNESCO page, reserved for the theme "World Heritage in Danger".

"Armed conflict and war, earthquakes and other natural disasters, pollution, poaching, uncontrolled urbanization and unchecked tourist development pose major problems to World Heritage sites. Dangers can be 'ascertained', referring to specific and proven imminent threats, or 'potential', when a property is faced with threats which could have negative effects on its World Heritage values".

In order to face, or at least mitigate, the risks concerning heritage, knowledge and scientific dissemination can clearly play an important role in prevention and conservation. In all the restoration and enhancement practices of existing buildings, certain strategies and interventions are put into practice. However, these cannot be abstracted from a careful and meticulous phase of preliminary knowledge of the asset. There are numerous examples in which a bad knowledge of the object has caused irreparable damage, both from a cultural point of view, affecting the integrity of the property, and from a purely conservational point of view.

\section{HISTORIC CITY CENTER OF VIENNA AS A CASE STUDY}

The historic center of Vienna (Innere Stadt) became part of the UNESCO cultural heritage list in 2001. The Justification by State Party reads as follows:

"The historic centre of Vienna proposed for inclusion in UNESCO's World Heritage List constitutes a uniquely preserved town monument, which is of outstanding universal value from the point of view of history, cultural history, and art. Its outstanding historical significance becomes manifest in "Vienna, the capital and residence city" is the political and spiritual centre of a multinational state, which was a decisive factor within European history from the Middle Ages to the break-up of the Austro-Hungarian monarchy".

The promotion of any cultural heritage property requires the selection of some standard criteria (set by UNESCO) to which reference is made. In the case of the Historic Center of Vienna, the selected criteria were (ii), (iv), (vi).

The first of them (criterium ii) requires to exhibit an important interchange of human values, over a span of time or within a cultural area of the world, on developments in architecture or technology, monumental arts, town-planning, or landscape design. The second (criterium iv) to be an outstanding example of a type of building, architectural or technological ensemble or landscape which illustrates (a) significant stage (s) in human history. The last (criterium vi) to be directly or tangibly associated with events or living traditions, with ideas, or with beliefs, with artistic and literary works of outstanding universal significance. ${ }^{1}$

The following is briefly reported what is extracted from file No. $1033^{2}$ regarding the case of the Historic Center of Vienna:

1. Criterium ii: The historic centre of Vienna exhibits an important interchange of human values on developments in architecture, town planning, and landscape design. The spatial organization as well as the density and quality of the historic buildings bear testimony to the socio-economic and cultural development of Vienna. This heritage is the bearer of a cultural tradition of outstanding universal value, designating Vienna as a city of art and culture.

2. Criterium iv: The historic centre of Vienna is an outstanding example of a city that illustrates significant stages in human history, including three major developments, medieval, Baroque, and Gründerzeit, in its urban pattern and its individual buildings. The historic centre of Vienna has an imperial design in its layout and the individual monuments and has thus become a symbol of Austrian history.

3. Criterium vi: Vienna is directly and tangibly associated with artistic and especially musical works of outstanding universal significance. Based on ecclesiastic liturgical music since medieval times, as well as minnesang and ancient dance music, Vienna became a centre of European music as early as the beginning of the 16th century under the Habsburgs. Opera, which emerged in Italy at the end of the 16th century, became firmly established at the court of Vienna in the High Baroque. The Viennese Classicists (Haydn, Mozart, Beethoven, Schubert) consolidated Vienna's reputation as the musical capital of Europe, a reputation that has continued and is expressed also in light music (Strauss) and modern music (Neo-Viennese School).

As of 2017, the Historic Center of Vienna is registered on the UNESCO List in Danger. "The current planning controls: adopted developments and lack of adequate planning rules". These are the words that define the reasons why the Innere Stadt must be included in the aforementioned list. What made this sentence necessary were projects that involved the construction of skyscrapers within the historic center. They concern the Vienna Ice-Skating Club, the Intercontinental Hotel and the Konzerthaus project. The actual implementation of these contemporary architectural projects would have compromised the integrity and authenticity of the historic center. All this was made possible by a Lack of effectiveness of the overall governance of the property.

\footnotetext{
1 The references were taken from the UNESCO page "The criteria for selection", which show what the characteristics of a given asset must be for its promotion to cultural heritage.

2 Document drawn up for the nomination of the historic center of Vienna as a cultural heritage.
} 
In light of all this, The World Heritage Committee, after examining the report on the current conservation of the historic city center, has implemented a series of measures and guidelines for the conservation of Austrian cultural heritage. Point 4 of the document "43 COM 7A.45" establishes how the current planning controls for the property, and the critical level of urban development require new tools to guide the development process in order to protect the attributes which contribute to the Outstanding Universal Value of the property.

\section{CULTURAL HERITAGE MANAGEMENT TOOL IN VIENNA}

The inscription on the "List in Danger" by UNESCO of the historic center of Vienna has clearly highlighted the need to preserve the authenticity and integrity of the Austrian cultural heritage. In accordance with the card provided by UNESCO for the promotion of the historic center as a cultural heritage, the authenticity and integrity of the latter have made its 371 hectares a catalyst for "Outstanding Universal Value". However, they must face the tough challenges brought by modernization and urban development like each great metropolis of the twenty-first century.

\subsection{Urban Planning and Heritage Conservation}

As regards the government of the territory, from a legislative point of view, the World Heritage of Vienna is doubly protected (Wehdron, 2009). Numerous regulations are currently in force for the maintenance, conservation and protection of existing buildings, especially those within the first district of Vienna (CBD), namely the historic center (Blaas \& Oppolzer, 2003).

Of great importance is the Vienna Building Code, a tool that regulates urban planning, zoning and the construction industry, like construction technology, minimum heights, size, etc. Its earliest version dates back to 1725 , but it was only 1829 when the city received, in a modern key, the first building regulations. Obviously, over the years, the document has undergone numerous changes for its improvement and modernization following the development of society and the city. Perhaps the most important change, from heritage preservation point of view, was the addition, in 1972, of the "Old Town Conservation Act" . Which basically stated that the conservation of historic buildings had to go from a federal level to a municipal level, through the assignment and recognition of the so-called conservation zones, for some areas of the city.

In 2002, the municipality issued a document entitled "Directives for planning and evaluating high-rise buildings", which established the criteria by which the construction of skyscrapers should be decided on. An example concerns the creation of exclusion zones because they are considered protected for a series of reasons, starting from the historical, artistic and cultural ones. In order not to excessively limit the architectural and technological development of the city, the same document

\footnotetext{
${ }^{3}$ Document forming part of the 258 "decisions" adopted in the 43rd session of the World Heritage Committee (43 COM) of 2019.

${ }^{4}$ Unesco card for the promotion of the historic center of Vienna as a cultural heritage.

${ }^{5}$ Vienna Law Gazette No. 16/1972.
}

also provided the criteria with which to establish the areas suitable for hosting new skyscrapers for the city.

Also in 2002, the Management Plan was issued, which, with the aim of protecting and preserving the world heritage in the Austrian capital, provides the legal and administrative procedures for territorial planning. Moving from a local to a state scale, the Federal Monuments Protection Act $^{6}$. The following document provides the measures and procedures for the protection of cultural heritage. In the first section, the purpose of the act is defined, and reads "The provisions of this Federal Act apply to man-made immovable and movable objects (including remains and traces of creative human intervention and artificially constructed or molded ground formations) of historic, artistic or other cultural significance ('monuments'), if, due to this significance, their preservation is in the public interest [...]. 'Preservation' means protection from destruction, alteration or being dispatched abroad".

Also from a legislative point of view, the need for architects and urban planners to submit to the Advisory Board for Urban Planning and Urban Design, any project whose extent may have significant effects on the city, is of great importance.

\subsection{The Vienna Memorandum}

As already mentioned in this paper, the central challenge that World Heritage, in this case the historic centers, must face concerns the confrontation with contemporary architecture and its development from a social, economic and environmental point of view. These two factions, 'old and new', have always represented a point of impasse for many theorists, historians, architects, urban planners etc. However, there are tools whose function concerns precisely the conjunction of these two fundamental elements for today's conception of urban development. During a conference held by UNESCO between 12 and 14 May 2005 in Vienna, the Vienna Memorandum was drawn up. This important document, as stated in its own article 5 , must be seen as an additional element to the already existing documents for the protection of cultural heritage, such as the Venice Charter $^{7}$ and the Washington Charter ${ }^{8}$. The Vienna Memorandum also wants to be understood "as a key statement for an integrated approach linking contemporary architecture, sustainable urban development and landscape integrity based on existing historic patterns, building stocks and context"9. What the document aims to overcome is therefore the gap between old and new, trying to find a dialogue through a new vision of the city seen as a whole. This is made possible through a mutual collaboration between the different actors who live in the city, from different points of view. Article 15 in fact invites "policy makers, urban planners, city developers, architects, conservationists, property owners, investors and concerned citizens" to 'work together' to preserve existing assets, while

\footnotetext{
${ }^{6}$ Federal Act on the Protection of Monuments Due to Their Historic, Artistic or Other Cultural Significance - Monument Protection Act - MPA, Federal Law came into effect on January 1, 2000.Vienna Law Gazette No. 533/1923.

${ }^{7}$ The "Venice Charter for the restoration and conservation of monuments and sites" is a document drawn up in 1964 whose purpose is to establish a standard code and a series of guidelines for the implementation of conservation and restoration interventions on architectural artefacts and archaeological sites.

${ }^{8}$ The "Washington Charter" also called the "Charter for the conservation of historic towns and urban areas", was drawn up in 1987. As the name suggests, it represents a tool for the management and conservation of historic centers.

${ }^{9}$ Vienna Memorandum - art. 5.
} 
considering the modernization and development of society in a "culturally and historic sensitive manner, strengthening identity and social cohesion".

It is therefore of fundamental importance to determine how to intervene, with works of contemporary architecture, in a historical context such as the historic center of Vienna. "Decision-making for interventions and contemporary architecture in a historic urban landscape", reads article 18 , "demands careful consideration, a culturally and historic sensitive approach, stakeholder consultations and expert know-how". The only tool to pursue this goal is knowledge. "A deep understanding of the history, culture and architecture of place" ${ }^{\prime 10}$ must represent the starting point. In this way, a balanced and sustainable urban development can be achieved, looking towards the future without forgetting the past.

The UNESCO association, on 10 July 2019 presented the updated version of the document entitled "Operational Guidelines for the Implementation of World Heritage Convention", a document that is periodically updated which aims to facilitate the implementation of the "Convention concerning the Protection of the World Cultural and Natural Heritage". Within the aforementioned document, point 108, which falls under the category "Protection and Management", specifies how "Each nominated property should have an appropriate management plan or other documented management system which must specify how the Outstanding Universal Value of a property should be preserved, preferably through participatory means".

Hence the opportunity for the creation of a tool to facilitate the conservation, protection and management of cultural heritage, to provide adequate knowledge in order to develop a historic and cultural-based contemporary architecture development.

\section{DESCRIPTION OF THE PLATFORM "HERITAGE FOR PEOPLE"}

Taking into account all the previously mentioned points about cultural heritage at risk, the authors have invented a new platform that aims to collect, link and share data to raise awareness about the current issues and provide an interactive space for discussions. For this reason, the current and historical plans on heritage sites at risk will be accessible to all and everyone will be able to see what work has already been done. As a side effect, this will also prevent unconscious duplication of work that has already been completed.

\subsection{Main Aims and Principles of the Project}

One of the basic goals is to design an easy-to-use platform so that everyone can move quickly and intuitively through the different areas, as all functions will be clearly arranged on the website. However, behind the simple interface, dozens of different types of comprehensive data are stored, indexed and made available for viewing and downloading without any contributions. Starting from a simple world map, anyone can find heritage sites based on their location. Either searching for the name of the site or zooming directly on the map to the specific heritage site will be possible. Furthermore, the platform will provide the option to filter heritage sites according to certain parameters in order to find comparable heritage cases worldwide. This function can be very useful, for example, in a

\footnotetext{
${ }^{10}$ Vienna Memorandum - art. 19.
}

specific case, such as a fortress in Greece, which is affected by erosion damage from the sea waves. Due to global warming, the direction of the wind and consequently the direction of the waves has changed and currently they endanger the valuable structural substance of the fortress. With the help of our platform, it is easy to find similar cases worldwide and contact researchers to share experiences and discuss possible solutions.

The platform is not only dedicated to research, but also focuses on various opportunities for other sectors such as communities, industries and the general public. Through the open data and communication on the platform, ideas and information can be easily spread and representatives of the different sectors can interact directly with each other. As the input for the platform consists of both expert and practice data, a broadly diversified data collection is guaranteed. While the science sector publishes research data and results, the community sector shares experiences, techniques and testimonials. Based on the shared knowledge from these areas, both industry and the crowd can benefit and be part of the public discussion.

The collected geographical data, scientific research and gained opinions of local communities can be a valuable source of information for everyone. Especially to further support the authorities and public institutions in their decision-making processes and to promote projects in the context of the historic site with higher public acceptance. In summary, the Heritage for People platform provides a variety of information and data and facilitates direct communication and networking between as well as within individual sectors of science, communities, industries and wider public.

\subsection{Structure of the Platform}

Although most of the information on the platform is free and open, it is necessary to create a personal member account in order to use all the functions. Following the principle of transparent and open communication, it is necessary to register with the real name and affiliation. Especially for downloading and uploading data, participating in the public discussions and communicating with other users, it is more than essential to reveal one's identity and background. It is also beneficial for building a multidisciplinary local and global network to provide as much information as possible about one's personal or professional context. In particular, it is recommended to file one's relationship and connection to specific heritage sites, thus enabling quick and direct communication, which is one of the main goals of the platform. In fact, there are already many existing professional networks such as LinkedIn, Xing, etc., which mainly focus on careers and business connections, but our platform will go further and link the personal profiles to the particular heritage sites, allowing for more efficient collaboration and interaction between users.

As our world faces global challenges such as global warming and many companies as well as institutions operate internationally nowadays, it has become crucial to be able to find reliable and accessible data about all possible places on this planet. For example, when an architectural office is designing for a historical site abroad, it is often not easy to find solid sources of information or the local GIS system to get comprehensive official data about the site. Another common obstacle is that local information websites are not available in English or are complicated to use. Since, site analysis plays an essential role to create a suitable architectural design, all basic information and links to official GIS websites are featured on the platform. In the gradually globalised world, the authors see 
great unexploited potential in linking data and people in a platform about cultural heritage on a global scale.

A multifunctional world map is the central tool of our proposal. It arranges all heritage sites according to their unique localisation. Each of the sites is displayed with a small image and its official name. When clicking on a selected site, basic information is automatically displayed in the right column. On the left side there are six sections with different information, the first being the already mentioned "Basic Information" and the second dedicated to "Tourism", where the official tourist website of the World Heritage Site is linked, as well as local platforms and contacts to hotels, local facilities and gastronomy with photos and recommendations.

The third section is called "Data" and all collected geometrical and scholarly information will be accessible there, indexed according to essential features like type, exact location and topic considered. For example, if clicking on a dataset about the 3D scan of the Arc de Triomphe in Paris, a preview will appear and, together with more information provided by the author, the name of the author and his contact on the platform. It will also be possible to leave comments and rate the quality of the dataset. In addition, members of the platform can download the raw data for further work and also upload additional data to the digital archive. To keep the database organised, there will be a commission that controls the relevance of the uploaded data.

The fourth category "Law" provides the official documents of UNESCO and other institutions as well as laws related to the respective site. For further information, links and contacts to local authorities and experts will be provided. The fifth section "Events" shows various cultural activities such as festivals, workshops, seminars or public discussions at the site addressing topics relevant to it. Basic information about each event is also provided and any member may participate digitally.

The last section focuses on "Communities", another core theme of our approach, where on the one hand valuable experiences and practices from the local people can be shared. On the other hand the public discussion and participation on concrete new projects in listed areas will be transparently presented and illustrated in this section. As described in the previous chapter, the City of Vienna has already had a lot of experience with turbulent public discussions about high-rise projects in the historic city centre. However, the opinions of the public were mostly - and somewhat distortedly - represented by the media and were highly political. Through our platform, more people could express their opinions, polls or other statistical tools will also be available and could serve as a more objective source of information for the municipality and everyone else.

In summary, the authors strongly believe that the six sections described, in combination with the multi-functional mapping tool, will be a significant step towards more transparent and open global heritage policies, data sharing and will enhance productive cooperation between people from many different sectors around the world.

\section{FURTHER METHODOLOGY}

Based on Vienna's experience with many different issues related to its cultural heritage, and considering the presence of a large technical university in the middle of the city, there is great potential for further development of the relationship between the historical heritage sites and new technologies.

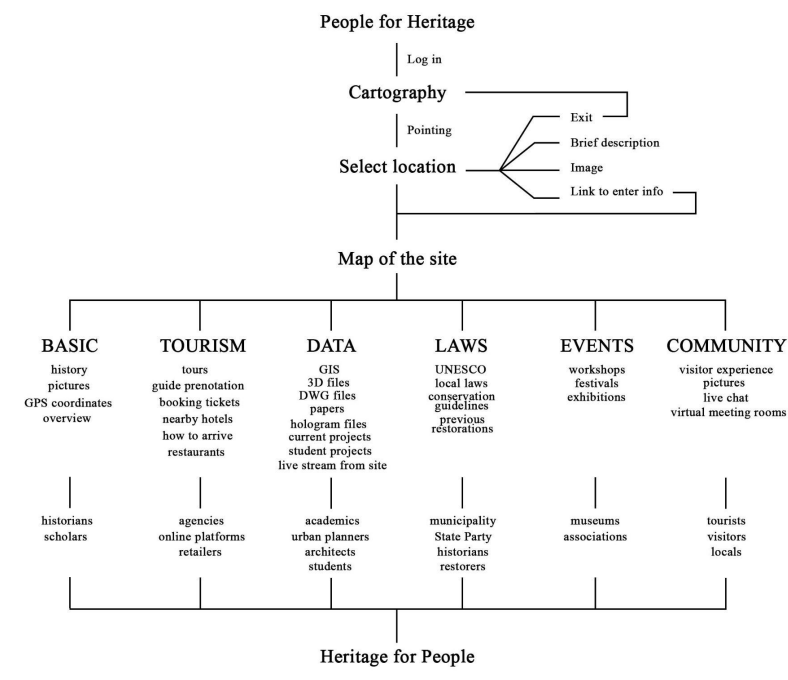

Figure 1. Platform Workflow

\subsection{Including new Technologies}

In 1998, a pioneering project for 3D simulation of buildings was developed in the Austrian cities of Vienna and Graz. At the time, it was a tool that revolutionised the planning process in a long-term perspective. The Austrian authors claimed that the new digital 3D model allowed architects to replace the time-consuming creation of a physical model, perspective drawings and photomontages, which had been the technique until then to get as realistic an impression as possible of the planned project. (Ranzinger, Gleixner 1998)

Nowadays, more than 20 years after the publication of this work, 3D modelling and visualisation are perceived by both professionals and the public as an indispensable working tool in a planning process. It was revolutionary to present new projects in a more understandable way to non-specialists and local communities. With the speeding up of technological progress, it has become possible to capture and process a huge amount of data. In the field of cultural heritage, it is mainly optical and geodetic technologies that play a crucial role in recording the mostly irregular shapes of historical sites.

Therefore, the new platform "Heritage for People" should definitely include such new technological processes, present their advantages to the general public and make them accessible to experts from different fields. 3D scanning methods began with the capture of small objects and are now capable of scanning entire buildings. In the future, it will probably be possible to gradually capture larger areas in a very detailed resolution and additional information. Such a new pilot project could be a very valuable basis for new approaches, such as using $3 \mathrm{D}$ models in a more accessible and interactive way to bridge the gap between professionals and the public. For example, such a digital tool could be very useful during a participatory process and increase society's acceptance of the changes to the historic sites, as the mentioned project achieved 20 years ago. 


\subsection{Live communication and interaction with people at the heritage site}

For many years now, the need to include the voices of the public in the proposed planning process and to develop the project from the "bottom-up" perspective, instead of a "top-down" procedure, has been widely recognised. Especially in historic neighbourhoods, this is extremely important, as residents base their strong identity on the specific historic environment. Therefore, another Viennese initiative called Fläviz has developed a tool to improve public participation and understanding in rezoning processes in the historic centre. The project highlights the problem of the missing comprehensible visual 3D information during a participation process, as the untrained majority finds it difficult to imagine the changes when reading two-dimensional plans with an explanatory text. Therefore, a unique application was developed that makes the complex regulatory situation easier to comprehend and shows the different alternatives of the proposed planning very illustratively. The Heritage for People platform has a similar approach at its core, so in future development it will be more than useful to cooperate with such projects, learn from their experiences and foster the best possible methodology. (Lorenz 2020)

After the Covid crisis, more and more people are becoming familiar with various online platforms that offer a whole spectrum of functions, from professional to private. Especially in the years of isolation or due to different locations, people have taken to communicating online. Therefore, an innovative communication tool is to be implemented as a part of the platform in a further step.

Similar to the online platform Discord, where people can meet online, build communities and share knowledge. In this online tool, anyone can join different groups depending on the topic and join the forum or various video and audio channels. Every member of the community can share his/her screen with others and communicate in real time. The main language of communication is English and this allows the vast majority to participate in the global discussions and benefit from the virtual interactive environment.

In terms of cultural heritage on the Heritage for People platform, it could work like the following example. A group of students is working on a project about the historic Roosendaal railway station in the Netherlands. Due to the covid crisis, it is not possible for them to travel there and explore the building complex themselves, so they rely on information from the internet. However, in the community area of the platform, they were able to create a new group where they can work together via video chat every day, just like they did in the studio at the university. Real-time communication will make it easier to quickly share and discuss research material. In addition, it will be possible to easily find Roosendaal Station on the platform's mapping tool and get basic as well as advanced information about the tourist activities and events, current laws, local municipalities, but also important links to other platforms such as the official Open Data GIS websites and, most importantly, a variety of datasets that have already been completed by other researchers and students who have conducted research at this historical site in the past. It will also be clearly visible which person was the author of the past projects and it will be easy to contact them directly through the platform and invite them to join the new group. Gradually, this will create a multidisciplinary online community that shares knowledge and collaborates efficiently to achieve more sustainable futures for heritage sites.

In this way, the Heritage for People platform will be a very helpful tool to bridge the gap between different stakeholders and create a fruitful creative environment that fosters communication and sustainable productivity.



Figure 2. Platform Example - section "Data"

\section{OTHER APPLICATIONS}

The Heritage for People platform works in an attempt to reach as many people as possible, with the aim of linking them from a cultural point of view. Further fueling this initiative is the possibility of gathering different types of cultural property within the platform, which can diversify depending on the definition and size.

\subsection{D Hologram Technology}

The technology related to video projection, thanks to new techniques and research, is today able to represent an incredible learning and data storage tool. Invented at the end of the 1940s by the Nobel prize Dennis Gabor ${ }^{11}$ hologram technology is able to "keep memory" of the light that is emitted by an object and to project it into space in the form of rays of light, in its three dimensions, in the surrounding space. All this through a simple projector. In the last decades this technology has advanced by important steps, arriving in 2009 with the creation of interactive holographic objects and the possibility of projecting directly from another location.

It is almost superfluous to underline how this development can represent great possibilities for the different categories of cultural heritage. Through this technology it would be possible, even today, to map tens of thousands of objects that are now part of the world heritage of humanity, and then make them projectable through hologram technology in 1:1 scale. The files can be uploaded to the platform and the user would have the opportunity to access it, download the file of interest through the convenient filter selection mentioned above, and project the object of study from their home. This modality could have different applications, starting from education for the youngest primary school students for a better way of learning, up to

11 Physicist and engineer of Hungarian origin who won, in 1971, the nobel prize for the invention of holography. 
professionals. The latter, in this case especially those involved in the restoration of cultural heritage, would have the possibility to carry out 'surveys' remotely.

The goal is to pursue an interactivity, increasingly made accessible by technological development. To date, there are platforms and websites for collecting archaeological objects and artifacts, which, however, are limited by the physical obstacles represented by the computer monitor. The step forward consists in breaking down this barrier to make cultural heritage a subject of study, interactive, with which to 'interact' in an absolutely safe way for the object itself.

\subsection{Archeological Sites}

Within the platform, data relating to the historic center of a city, holographic data of objects or buildings can then be collected. Archaeological sites will obviously be included. The latter, in fact, represents an important material for architecture which has been working for years, together with other disciplines of course, for the collection of information through surveys for the conservation of archaeological heritage scattered around the world. These studies are conducted for their 'digitization', i.e. to map everything concerning the archaeological site in question at 360 degrees. The results provided are then used for their cataloging, to conduct studies of a historical, artistic and cultural nature. But they can also be used for conservation and restoration interventions for future reuse and enhancement. The various restoration papers, and above all the various restoration theorists, have shown how intervening on objects of this kind represents an excellent way to enhance the cultural heritage, abandoning the 'museum' vision according to which what belongs to history cannot be modified except through interventions that transform it to a state of eternal conservation.

In this case, The Heritage for People platform can also represent the tool for collecting information of a different nature, linked to the archaeological site itself. An example can be the vector graphic rendering of the site for future architectural projects. They will also be accompanied by all the scientific research of the object in question, i.e. historical and photographic documentation, research already carried out by professionals, etc. In addition, a section may be dedicated to students of the various faculties who carry out projects for the re-functionalization of the archaeological site. The latter can clearly find all the information necessary for the project from the platform, and always through it, they can upload their projects in the dedicated section. In this way it is possible for the student to relate to the world of work by publishing his / her portfolio on the platform.

\section{CONCLUSION}

The case of Vienna certainly represents a starting point, but it is not the only case of cultural heritage registered in the List in Danger. To date, there are more than 50 sites that need measures and safeguards for their conservation and enhancement. This highlights how, today more than ever, it is necessary to implement policies and strategies to mitigate the effects of the passage of time on our wonders. Like any operation in the public interest, although there are tools for implementation, what is really essential is awareness. Awareness that must grow in all citizens through the knowledge of what is around them. The demonstration that cultural heritage and contemporary architecture can coexist has been given, now what remains to be verified is whether man is able to coexist with these two elements. The Heritage for People platform aims to increase this awareness and knowledge by creating an international community and a web for information exchange. There is hardly a more promising and sustainable way to preserve and protect what comes from the past, than by fully utilizing today's technologies and layers of communication.

\section{REFERENCES}

Ranzinger, Monika; Gleixner, Günther (1998): GIS DATASETS FOR 3D URBAN PLANNING. Comput., Environ. and Urban Systems, Vol. 21, No. 2, pp. 159-173, 1997. Printed in Great Britain.

Lorenz, Wolfgang E.; Wurzer, Gabriel (2020): Fläviz in the Rezoning Process.

Wolfgang, B., Oppolzer, G. (2003): Socioeconomic dynamics and property rights regulation as driving forces of urban spatial development: the case of Vienna. Institute of Public Finance and Infrastructure Policy.

The Vienna Memorandum (2005): (n.d.). (2016, May 21). http://orcp.hustoj.com/the-vienna-memorandum-2005/

Wehdorn, M (2009): The Historic Centre of Vienna. World Cultural Heritage and Vibrant Hub.

Hologram Technology (n.d.).

https://www.ssla.co.uk/hologram-technology/

UNESCO World Heritage List webpage

http:/whc.unesco.org/en/list/1033/documents/ 